\title{
MARIE DE FLAVIGNY, comtesse d'Agoult, CORRESPONDANCE GÉNÉRALE
}

\section{Lise Sabourin}

\section{(2) OpenEdition \\ Journals}

\section{Édition électronique}

URL : https://journals.openedition.org/studifrancesi/45304

DOI : 10.4000/studifrancesi.45304

ISSN : 2421-5856

\section{Éditeur}

Rosenberg \& Sellier

\section{Édition imprimée}

Date de publication : 1 août 2021

Pagination : 391-392

ISSN : 0039-2944

\section{Référence électronique}

Lise Sabourin, « MARIE de FLAVIGny, comtesse d'Agoult, correspondance générale », Studi Francesi [En ligne], 194 (LXV | II) | 2021, mis en ligne le 01 septembre 2021, consulté le 15 octobre 2022. URL : http:// journals.openedition.org/studifrancesi/45304; DOI : https://doi.org/10.4000/studifrancesi.45304

Ce document a été généré automatiquement le 15 octobre 2022.

\section{(c) (†)}

Creative Commons - Attribution - Pas d'Utilisation Commerciale - Pas de Modification 4.0 International - CC BY-NC-ND 4.0

https://creativecommons.org/licenses/by-nc-nd/4.0/ 


\title{
MARIE DE FLAVIGNY, comtesse d'Agoult, CORRESPONDANCE GÉNÉRALE
}

\author{
Lise Sabourin
}

\section{RÉFÉRENCE}

MARIE DE FLAVIGNY, COMTESSE D’AGOULT, CORRESPONDANCE GÉNÉRALE, t. VIII: 1853-1855, édition établie et annotée par Ch.F. Dupêchez, Paris, Honoré Champion, 2019, 739 pp.

1 Ce huitième tome de la Correspondance de Marie d'Agoult la montre heureuse dans les années 1853-1855. D'abord par sa vie familiale qui lui permet alors de faire se joindre ses «deux branches»: outre sa fille Claire de Charnacé qui, en instance de séparation d'avec son mari, vient vivre chez elle avec son petit-fils Daniel, elle retrouve la possibilité de recevoir Blandine, Cosima et Daniel, que Liszt lui laisse un temps héberger, avant pourtant de prendre ombrage de son influence et de les lui retirer d'une manière assez déplaisante pour les établir à Berlin. Par sa vie intellectuelle ensuite dans la maison Rose sise près de la place de l'Étoile où elle peut faire fréquenter à ses enfants, brillamment doués, les grands hommes du moment: Littré, Michelet, Martin, Mignet, Vacherot, Renan.

2 Les voyages se multiplient aussi, aux beaux jours, parfois avec sa fille, en Normandie, parfois seule en Auvergne (notamment en Bourbonnais dont ce volume édite la relation), dans le midi, par Valence, à Nîmes, Arles et Avignon. Elle fuit le choléra parisien à Biarritz où séjourne aussi le couple impérial en mal de progéniture, visite le pays basque, fait une incursion en Espagne, ce qui la ramène à l'histoire des Pays-Bas dont elle écrit le début pour la "Revue contemporaine". Elle travaille beaucoup, aidée de ses secrétaires, Lacaussade et Prévost-Paradol, sur la documentation que lui fournit le baron de Penhoën, et publie le dernier volume de son Histoire de la Révolution de 1848. Elle s'essaie au genre dramatique avec ses Trois journées de la vie de Marie Stuart qu'elle ne parvient pas à faire jouer mais lit devant Ponsard et quelques intimes. 
3 Muni de nombreuses lettres de ses correspondants, ce tome n'en laisse pas moins apparaître la vivacité de cette femme de lettres alors en pleine possession de ses moyens, qui parfois confie à ses correspondants quelques réflexions sur la sincérité de son engagement d'écrivain (voir p. 206 à Hortense Allart) et sait décocher en phrases bien senties des jugements pleins de perspicacité et d'alacrité à la fois (telle cette remarque p.181, sur le site extraordinaire du Puy, où «les forces volcaniques ont préparé une merveilleuse scène au génie religieux qui s'en est emparé et y a laissé sa triple empreinte», druidique, païenne antique et finalement mariale). Réflexion clairvoyante sur les individus et les événements, élans de générosité mais aussi sécheresse déconcertante parfois: telles sont les marques de sa vivacité intelligente. 